\title{
BMJ Open The impact of maternal health care utilisation on routine immunisation coverage of children in Nigeria: a cross- sectional study
}

\author{
Onyekachi Ibenelo Anichukwu, ${ }^{1}$ Benedict Oppong Asamoah ${ }^{\odot}$
}

To cite: Anichukwu 0I, Asamoah B0. The impact of maternal health care utilisation on routine immunisation coverage of children in Nigeria: a crosssectional study. BMJ Open 2019;9:e026324. doi:10.1136/ bmjopen-2018-026324

- Prepublication history for this paper is available online. To view these files please visit the journal online (http://dx.doi. org/10.1136/bmjopen-2018026324).

Received 27 August 2018

Revised 10 May 2019

Accepted 22 May 2019
Check for updates

(C) Author(s) (or their employer(s)) 2019. Re-use permitted under CC BY-NC. No commercial re-use. See rights and permissions. Published by BMJ.

${ }^{1}$ International Masters

Programme in Public Health, Department of Clinical Sciences, Malmö, Lund University, Lund, Sweden

${ }^{2}$ Department of Clinical

Sciences, Malmo, Social

Medicine and Global Health,

Lund University, Lund, Sweden

Correspondence to

Mr. Onyekachi

Ibenelo Anichukwu;

anichukwuibenelo@yahoo.com

\section{ABSTRACT}

Objective To examine the impact of maternal healthcare (MHC) utilisation on routine immunisation coverage of children in Nigeria.

Design Individual level cross-sectional study using bivariate and multivariable logistic regression analyses to examine the association between MHC utilisation and routine immunisation coverage of children.

Setting Nigeria Demographic and Health Survey 2013. Participants 5506 women aged $15-49$ years with children aged 12-23 months born in the 5 years preceding the survey.

Primary outcome measures Fully immunised children and not fully immunised children.

Results The percentage of children fully immunised with basic routine childhood vaccines by the age of 12 months was $25.8 \%$. Antenatal care (ANC) attendance irrespective of the number of visits (adjusted OR (AOR) visits $2.4,95 \% \mathrm{Cl} 1.79$ to $3.27 ; \mathrm{AOR}_{4-7}$ visits $3.2,95 \% \mathrm{Cl} 2.52$ to 4.13; $\mathrm{AOR}_{>8 \text { visits }} 3.5,95 \% \mathrm{Cl} 2.64$ to 4.50 ), skilled birth attendance (SBA) (AOR 1.9, 95\% Cl 1.65 to 2.35); and maternal postnatal care (PNC) (AOR 1.7, 95\% Cl 1.46 to 2.06) had positive effects on the child being fully immunised after adjusting for covariates (except for each other, ie, ANC, SBA and PNC). Further analyses (adjusting stepwise for each MHC service) showed a mediation effect that led to the effect of PNC not being significant.

Conclusions The percentage of fully immunised children in Nigeria was very low. ANC attendance, SBA and maternal PNC attendance had positive impact on the child being fully immunised. The findings suggest that strategies aimed at maximising MHC utilisation in Nigeria could be effective in achieving the national coverage target of at least $80 \%$ for routine immunisation of children.

\section{INTRODUCTION}

Developing countries, especially sub-Saharan African countries, where the rate of neonatal and under-five mortality is disproportionately high have been urged by the United Nations to put in place measures that will reduce neonatal mortality rate to about 12/1000 live births and under-five mortality to about $25 / 1000$ live births by $2030 .^{1-3}$ Much of neonatal and under-five mortality in

\section{Strengths and limitations of this study}

- The reliability of this study is increased by the suitability of the research questions and detailed description of the dependent variable, predictor variables and other covariates, the quality of the Nigeria Demographic and Health Survey (NDHS) women's questionnaire, which is a carefully developed standard model questionnaire and by having a well categorised dependent variable. The NDHS provided a large sample size and high-quality data which reduced the risk of sampling bias and measurement bias in this study.

- Confounding was controlled for through the proper formation of subcategories of the predictor variables and other covariates; and the consideration of a wide range of covariates in the multivariable logistic regression analysis which reduced the risk of confounding, increasing the internal validity of this study.

- The NDHS questionnaires are not self-administered, which makes the data prone to interviewer bias. This could reduce the internal validity of this study. Also, the inclusion of immunisation status of the children from verbal reports of the mother might have introduced recall bias into this study because mothers who used maternal healthcare (MHC) may have better recall than mothers who used no MHC.

- There is still risk for residual confounding even after controlling for confounding in this study and the non-exploration of partially immunised children might have led to loss of information regarding routine immunisation coverage in Nigeria.

- Vaccine stockouts, poor cold chain systems and non-readiness of healthcare providers to administer the vaccines during mothers' use of maternal health services in Nigeria are provider side barriers to the child being fully immunised, which could have led to an underestimation of the impact of MHC utilisation on routine immunisation coverage found in this study.

sub-Saharan African countries is attributable to childhood diseases which can be prevented by immunisation. ${ }^{2}$ Immunisation is a very efficient and cost-effective public health 
intervention which prevents about 2.5 million childhood mortality per year and it is considered one of the main cost-effective interventions that can be used to achieve the Sustainable Development Goal (SDG) 3.2-to end preventable deaths of newborns and children under-five by $2030 .^{14-7}$

In an effort to combat vaccine-preventable diseases and to reduce neonatal and under-five mortality and morbidity globally, the WHO initiated the Expanded Programme on Immunisation (EPI) in 1974 with a goal to immunise every child in the world by the year $1990 . .^{8-10}$ The EPI targets children under 12 months of age with a dose of BCG vaccine, three doses of Poliomyelitis vaccine (OPV), three doses of Diphtheria-Tetanus-Pertussis (DTP) vaccine and a dose of Measles vaccine. The programme was introduced into Nigeria by the Federal Ministry of Health in collaboration with WHO and UNICEF in 1976 as a pilot programme, while the national implementation commenced in $1979 .^{10-13}$ The goal of the programme in Nigeria was to reach immunisation coverage rate of $80 \%$ by 1990 in order to reduce to $50 \%$ the mortality and morbidity rate resulting from the EPI targeted diseases. ${ }^{10}$ Only $20.4 \%$ reduction in neonatal mortality rate was achieved by 1990 and the actual neonatal mortality rate was $49 / 1000$ live births in the same year. ${ }^{14}{ }^{15}$ However, there was not much reduction in neonatal mortality from 1990 to 2013 , the neonatal mortality rate was $37 / 1000$ live births by $2012 .{ }^{14} 15$

In Nigeria, routine immunisation is integrated into the maternal healthcare (MHC) both in the public and private health sectors in all the 36 states and the Federal Capital Territory. ${ }^{16}$ The MHC continuum consists of antenatal care (ANC), skilled birth attendance (SBA) and postnatal care (PNC). ${ }^{1718}$ The progress in the proportion of fully immunised children (ie, children who received all six recommended vaccines) from 1990 to 2013 was very little. ${ }^{19} 20$ The Nigeria Demographic and Health Survey (NDHS) 2013 report showed that the trends in full immunisation coverage of children aged 12-23 months increased from $13 \%$ in 2003 to $25 \%$ in $2013 .{ }^{21}$ The progress in the proportion of fully immunised children from 2003 to 2013 corresponded to the increase in ANC utilisation (from 58\% in 2003 to $61 \%$ in 2013) and SBA (from $35 \%$ in 2003 to $38 \%$ in 2013). ${ }^{22}$ From 2008-2013, there was no significant improvement in the proportion of women who received PNC; $58 \%$ of women received no PNC within 41 days after delivery in 2013. ${ }^{22}$

MHC and routine immunisation have been identified as important public health tools in achieving the SDG 3, 'ensuring healthy lives and promoting well-being for all at all ages'. ${ }^{23}$ Studies have shown that children are more likely to be fully immunised in Ghana, the Gambia, Burkina Faso and the Republic of Benin than in Nigeria. ${ }^{24-26}$ Living in the Northern region of Nigeria has been found to be associated with lower likelihood of children to be fully immunised compared with other regions of the country. ${ }^{24}{ }^{27}$ In addition, children in the urban areas are more likely to be fully immunised than children in the rural areas. ${ }^{2425}{ }^{27}$ Furthermore, the richest quintile in the household socio-economic class, maternal age of 34 years and older, being a first-born child and ownership of vaccine card are positively associated with fully immunised children in Nigeria. ${ }^{2425} 27$ These studies examined different socio-demographic factors that are associated with immunisation coverage in Nigeria. However, to the best of our knowledge, no study has examined the impact of MHC utilisation holistically on routine immunisation coverage of children in Nigeria. Therefore, the main aim of this study was to examine the impact of MHC utilisation on routine immunisation coverage of children in Nigeria.

\section{METHODS}

\section{Study setting and study population}

Nigeria is a sub-Saharan African country with a population of about 180 million and a birth cohort of 7.3 million. ${ }^{28}$ Nigeria is made up of 36 states and a Federal Capital Territory which altogether are grouped into six geopolitical zones (North Central, North East, North West, South East, South South and South West) with 774 local government areas. ${ }^{28}$

To examine the impact of MHC utilisation on routine immunisation coverage of children in Nigeria, a population of mothers aged 15-49 years from the six geopolitical zones of Nigeria, with their children between the age of 12-23 months were selected from the women's data of the NDHS 2013. The last birth experience of the mothers in the 5 years preceding the survey were used in this study. Each of the mothers contributed one child only and a total of 5506 mothers with their children (2638 girls, 2868 boys) were included in this study.

\section{Study design and data collection}

This study was an individual level cross-sectional study, which used the individual women's data of the NDHS 2013; the most recent data available at the time this study was carried out. One of the main goals of the NDHS 2013 was to provide information about maternal and child health, as well as immunisation coverage. The women's data contained all births in the 5 years preceding the NDHS 2013 and it also contained information about all women from 15 to 49 years of age from a sample of 40680 households with 904 clusters (primary sampling units) of which 372 and 532 clusters were in the urban and rural areas respectively. ${ }^{21} \mathrm{~A}$ fixed sample unit of 45 households were selected from each enumeration area.

The women interviewed were permanent residents of the households in the survey sample or a visitor to the households on the night before the survey. Information on vaccination coverage for children were collected from children's vaccination cards and/or from verbal reports from the mothers. The NDHS 2013 data were collected from all the six geopolitical zones in Nigeria; hence, it is a nationally representative data. ${ }^{21}$ 


\section{Dependent variables}

The outcome variable is routine immunisation coverage which was dichotomised as 'not fully immunised' and 'fully immunised'. The WHO recommends that a child should have received all the basic routine vaccines by the time the child is 12 months old. ${ }^{21}$ Therefore, for this study, a child is said to be fully immunised if the child had received all the six vaccines, namely a dose of BCG, three doses of OPV, three doses of DTP and a dose of Measles by age of 12 months. A child is said to not to be fully immunised if the child was partially vaccinated or not vaccinated at all by age of 12 months.

\section{Predictor variables}

The predictor variables include ANC attendance, SBA and maternal PNC.

\section{ANC attendance}

In the NDHS 2013 women's questionnaire, a woman is said to have received ANC from skilled health providers if she has seen a skilled health provider for ANC during pregnancy for the most recent birth in the 5 years preceding the survey. ${ }^{21}$ For this study, skilled health providers trained in ANC included a doctor, nurse, midwife and auxiliary midwife. In the WHO's new ANC model, the minimum recommended number of $\mathrm{ANC}$ visits has increased from four to eight visits. ${ }^{29}{ }^{30}$ Hence, the number of ANC visits was grouped as follows: None, one to three times, four to seven times and $\geq$ eight times.

\section{Skilled birth attendance}

According to the $\mathrm{WHO}$, a woman is said to have used skilled birth attendance (SBA) if the woman's delivery leading to a live birth was attended by a skilled health provider such as doctor, nurse and midwife trained in child delivery. ${ }^{21}$ For this study, a SBA included a doctor, nurse and midwife trained in child delivery. Hence, a woman whose most recent child was delivered by a SBA in the 5 years preceding the survey was considered as 'Yes, to SBA'. Other forms of birth attendance were deemed unskilled birth attendance and were considered as 'No, to SBA'.

\section{Maternal PNC}

The WHO recommendation on PNC stresses that mothers and newborns should receive PNC from a skilled health provider in the facility within 24 hours after delivery or at home as early as possible within 24 hours of delivery and at least three additional postnatal contacts for mothers and newborns on day 3 , and between 1 and 2 weeks after delivery and 6 weeks after delivery. ${ }^{31}$ In this study, skilled health providers trained in maternal PNC included a doctor, nurse, midwife and auxiliary midwife. For this study, a mother who received postnatal check-up within 41 days after delivery from a skilled health provider trained in maternal PNC for the mother's last birth experience in the 5 years preceding the survey was considered as 'Yes, to maternal PNC', while other forms of maternal PNC were considered as 'No, to maternal PNC'.

\section{Control variables}

After a thorough literature review about potential confounders in this area of study, a list of covariates associated with the utilisation of MHC and which are also associated with routine immunisation coverage were considered. The covariates considered include highest educational level, wealth index, geopolitical zone, place of residence, person who decides on mother's healthcare, parity, mother's age and mother's occupation. The categorisation of the control variables is presented below.

Highest educational level was categorised into four groups, namely; (1) no education (reference group), (2) primary education (completed 6years of formal education), (3) secondary education (completed 12 years of formal education) and (4) higher education (completed 16 years of formal education).

Wealth index was measured based on ownership of household assets (bicycles and televisions), access to different types of water, the use of different types of sanitation facilities and the type of material used in housing construction. Wealth index was first categorised into five quintiles and recategorised into three groups in this study as (1) poor, which comprised of respondents in the poorer and poorest classes (reference group), (2) middle class and (3) rich, which comprised of respondents in the richer and richest classes.

Geopolitical zone was categorised into the six geopolitical zones in Nigeria, namely: North Central (reference group), North East, North West, South East, South South and South West.

Place of residence was categorised into Urban residence and Rural residence (reference group).

Person who decides on mother's healthcare was categorised into three groups as (1) mother alone, (2) mother and husband/partner/other person and (3) husband/ partner/other person (reference group).

Parity is the total number of births with a gestational period of at least 24 weeks by the respondents irrespective of outcome. Parity (total number of children ever born) was categorised as follows: one (reference group), two to five and $\geq$ six.

Mother's age (in years) was categorised into three groups as follows: 15-24 years (reference group), 25-34 years and 35-49 years.

Mother's occupation was categorised into three groups as (1) not working (reference group), (2) unskilled-Low skilled, which comprised of unskilled manual job, household/domestic job, sales job and services and (3) middleHigh skilled, which comprised of professional/technical/ managerial job, clerical job, skilled manual job and agricultural-employed/self-employed.

\section{Statistical analysis}

\section{Preliminary data analysis}

The analysis was performed using the statistical software SPSS V.25. Prior to the analysis, the data were screened and cleaned using exploratory data analysis. ${ }^{3233}$ Recoding of some selected variables into categorical variables and 
the creation of new variables from the existing variables were performed where it deemed necessary. Weight variable was created using the women's weight, i.e. v005 variable (v005/1 000000$).{ }^{34}$ The weight was applied in all analyses involving significance testing or CIs in order to restore the representativeness of the sample. ${ }^{34}$ Additionally, the complex survey design in the NDHS 2013 dataset was adjusted for in the analysis to prevent underestimation of the standard errors. ${ }^{21}$ This was done in this study by specifying the sample design in the analytical software (SPSS) during all analyses involving confidence intervals, standard errors and significant testing. Multicollinearity diagnostic was used to examine the predictor variables for the presence of multicollinearity and to remove variables with variance inflation factor value of greater than 10 (>10) from the analysis. ${ }^{3233}$ Correlation analysis was used to ensure that the correlation between the predictor variables were less than equal to $0.8(\leq 0.8) .{ }^{32}$ Casewise diagnostic was used to make sure that there were no potential outliers that could alter the results of the analyses. ${ }^{32}$

\section{Descriptive statistics}

Descriptive statistics was used to examine the sex of children and the socio-demographic characteristics of their mothers. ${ }^{32}{ }^{33}$ Cross-tabulation was performed to show the immunisation status of children according to the sex of children and socio-demographic characteristics of their mothers.

\section{Bivariate analysis}

Bivariate logistic regression analysis was used to examine the impact of the predictor variables (ANC attendance, SBA and maternal PNC) on immunisation coverage of children aged 12-23 months. ${ }^{32} 33$ The statistical significance level ( $p$ value) was set at $<0.05 .{ }^{32}{ }^{33}$ Crude ORs with $95 \%$ confidence interval $(95 \% \mathrm{CI})$ were generated for the association between routine immunisation coverage and ANC attendance, SBA and maternal PNC in the bivariate logistic regression analysis.

$\chi^{2}$ test for independence was used to examine the association between routine immunisation coverage and the covariates. ${ }^{3233}$ In order to prevent the removal of covariates that could potentially affect the results of the multivariable logistic regression analysis, the $\chi^{2}$ test was used to identify and select covariates with $p$ values $\leq 0.25$ for further analysis in the logistic regression models. ${ }^{32}$

\section{Multivariable logistic regression analysis}

Multivariable logistic regression analysis was performed to develop different models for the relationship between routine immunisation coverage, predictor variables and covariates, and to control for confounding effects using the manual forward elimination approach, that is, forward selection method. For each multivariable logistic regression analysis, the main predictor variable was added first in the equation followed by other variables in an increasing order of the $p$ values of the variables from the $\chi^{2}$ test for independence. ${ }^{32}$ The statistical significant level ( $p$ value $)$ in the multivariable logistic regression analysis was set at $<0.05{ }^{3233}$ A covariate that is non-significant but caused $\geq 10 \%$ change in the OR of any variable in the equation was retained as a potential confounder. ${ }^{32}$ Several multivariable logistic regression analyses (using one predictor variable, ie ANC, SBA or $\mathrm{PNC}$ at a time) were performed to generate the adjusted ORs (AORs) with 95\% CI in different models. To examine the direct impact of each predictor variable individually on immunisation coverage of children independent of the covariates, a multivariable logistic regression analysis was performed to generate three different models. To examine the changes in the impact of the predictor variables on routine immunisation coverage independent of the covariates along the MHC continuum, a stepwise multivariable logistic regression analysis was performed to generate three different models.

\section{Patient involvement}

No patients were involved in developing the research question and study design or in the implementation of the study design, the interpretation of the results and writing of the manuscript. There are no plans to share the study with patients.

\section{RESULTS}

\section{Descriptive analysis results}

The weighted immunisation status of children according to the sex of the children and socio-demographic characteristics of their mothers are shown in table 1 . The percentages of male and female children aged 12-23 months in the study were $52.1 \%$ (2868) and $47.9 \%$ (2638), respectively. The percentage of children who were fully immunised was only $25.8 \%$ (1419). About $74 \%(74.4 \%, 1973)$ of female children were not fully immunised whereas only $25.6 \%$ (678) of female children were fully immunised. About $74 \%$ $(73.9 \%, 2102)$ of male children were not fully immunised whereas only $26.1 \%$ (741) of male children were fully immunised.

The analysis showed that about $61 \%(60.5 \%, 3236)$ of mothers had at least one ANC visit. The prevalence of being fully immunised increased with increasing number of ANC visits (No ANC attendance $6.5 \%$, one to three ANC visits 20.8\%, four to seven ANC visits $34.1 \%$ and $\geq$ eight ANC visits $49.2 \%)$. About $37 \%(36.9 \%, 2023)$ of mothers used SBA at delivery. About $48 \%(47.9 \%, 975)$ of mothers who used SBA had their children fully immunised compared with only $12.8 \%$ (440) for mothers who did not use SBA. About $36 \%(35.8 \%, 1930)$ of mothers received PNC. Forty-seven per cent $(47.0 \%, 908)$ of mothers who received PNC had their children fully immunised compared with only $14.0 \%$ (482) for mothers who did not receive PNC.

\section{Bivariate logistic regression results}

The crude OR (COR) with 95\% CI for the association between immunisation coverage and ANC attendance, SBA and maternal PNC are shown in table 2. Mothers who had one to three ANC visits (COR 3.8, 95\% CI 2.92 to 4.97), 
Table 1 Socio-demographic characteristics of mothers (aged 15-49 years) by immunisation status of their children aged $12-23$ months in Nigeria. Total $(n)=5506$. (Nigeria Demographic and Health Survey 2013)

\begin{tabular}{|c|c|c|c|c|c|c|}
\hline \multirow[b]{3}{*}{ Characteristics } & \multirow{2}{*}{\multicolumn{2}{|c|}{$\begin{array}{l}\text { (Unweighted) } \\
\text { Total population } \\
\end{array}$}} & \multicolumn{4}{|c|}{ (Weighted) } \\
\hline & & & \multicolumn{2}{|c|}{ Not fully immunised } & \multicolumn{2}{|c|}{ Fully immunised } \\
\hline & $\mathrm{n}$ & $(\%)$ & $\mathrm{n}$ & (\%) & $\mathrm{n}$ & $(\%)$ \\
\hline \multicolumn{7}{|l|}{ Mother's age (in years) } \\
\hline $15-24$ & 1543 & 28.0 & 1277 & 80.9 & 301 & 19.1 \\
\hline $25-34$ & 2697 & 49.0 & 1877 & 70.2 & 797 & 29.8 \\
\hline $35-49$ & 1266 & 23.0 & 922 & 74.2 & 321 & 25.8 \\
\hline (Total missing) & (0) & & & & & \\
\hline (Total included in the analysis) & (5506) & & & & & \\
\hline \multicolumn{7}{|l|}{ Sex of child } \\
\hline Male & 2868 & 52.1 & 2102 & 73.9 & 741 & 26.1 \\
\hline Female & 2638 & 47.9 & 1973 & 74.4 & 678 & 25.6 \\
\hline (Total missing) & (0) & & & & & \\
\hline (Total included in the analysis) & (5506) & & & & & \\
\hline \multicolumn{7}{|l|}{ Place of residence } \\
\hline Urban & 1819 & 33.0 & 1117 & 57.1 & 840 & 42.9 \\
\hline Rural & 3687 & 67.0 & 2959 & 83.6 & 580 & 16.4 \\
\hline (Total missing) & (0) & & & & & \\
\hline (Total included in the analysis) & (5506) & & & & & \\
\hline \multicolumn{7}{|l|}{ Geopolitical zone } \\
\hline North Central & 839 & 15.2 & 566 & 72.2 & 218 & 27.8 \\
\hline North East & 1127 & 20.5 & 817 & 85.5 & 139 & 14.5 \\
\hline North West & 1708 & 31.0 & 1769 & 90.1 & 195 & 9.9 \\
\hline South East & 504 & 9.2 & 230 & 46.2 & 268 & 53.8 \\
\hline South South & 665 & 12.1 & 242 & 45.7 & 287 & 54.3 \\
\hline South West & 663 & 12.0 & 451 & 59.0 & 313 & 41.0 \\
\hline (Total missing) & (0) & & & & & \\
\hline (Total included in the analysis) & (5506) & & & & & \\
\hline \multicolumn{7}{|l|}{ Highest educational level } \\
\hline No education & 2543 & 46.2 & 2461 & 93.0 & 186 & 7.0 \\
\hline Primary education & 1072 & 19.5 & 727 & 73.4 & 263 & 26.6 \\
\hline Secondary education & 1498 & 27.2 & 750 & 51.1 & 718 & 48.9 \\
\hline Higher education & 393 & 7.1 & 138 & 35.3 & 253 & 64.7 \\
\hline (Total missing) & (0) & & & & & \\
\hline (Total included in the analysis) & (5506) & & & & & \\
\hline \multicolumn{7}{|l|}{ Wealth index } \\
\hline Poor & 2499 & 45.4 & 2320 & 92.2 & 197 & 7.8 \\
\hline Middle & 1077 & 19.5 & 761 & 74.8 & 257 & 25.2 \\
\hline Rich & 1930 & 35.1 & 995 & 50.7 & 966 & 49.3 \\
\hline (Total missing) & (0) & & & & & \\
\hline (Total included in the analysis) & (5506) & & & & & \\
\hline \multicolumn{7}{|l|}{ Mother's occupation } \\
\hline Not working & 1570 & 28.7 & 1266 & 79.8 & 321 & 20.2 \\
\hline Unskilled-low skilled & 2369 & 43.3 & 1757 & 72.5 & 668 & 27.5 \\
\hline Middle-high skilled & 1529 & 28.0 & 1035 & 71.0 & 423 & 29.0 \\
\hline (Total missing) & (38) & & & & & \\
\hline (Total included in the analysis) & (5468) & & & & & \\
\hline
\end{tabular}


Table 1 Continued

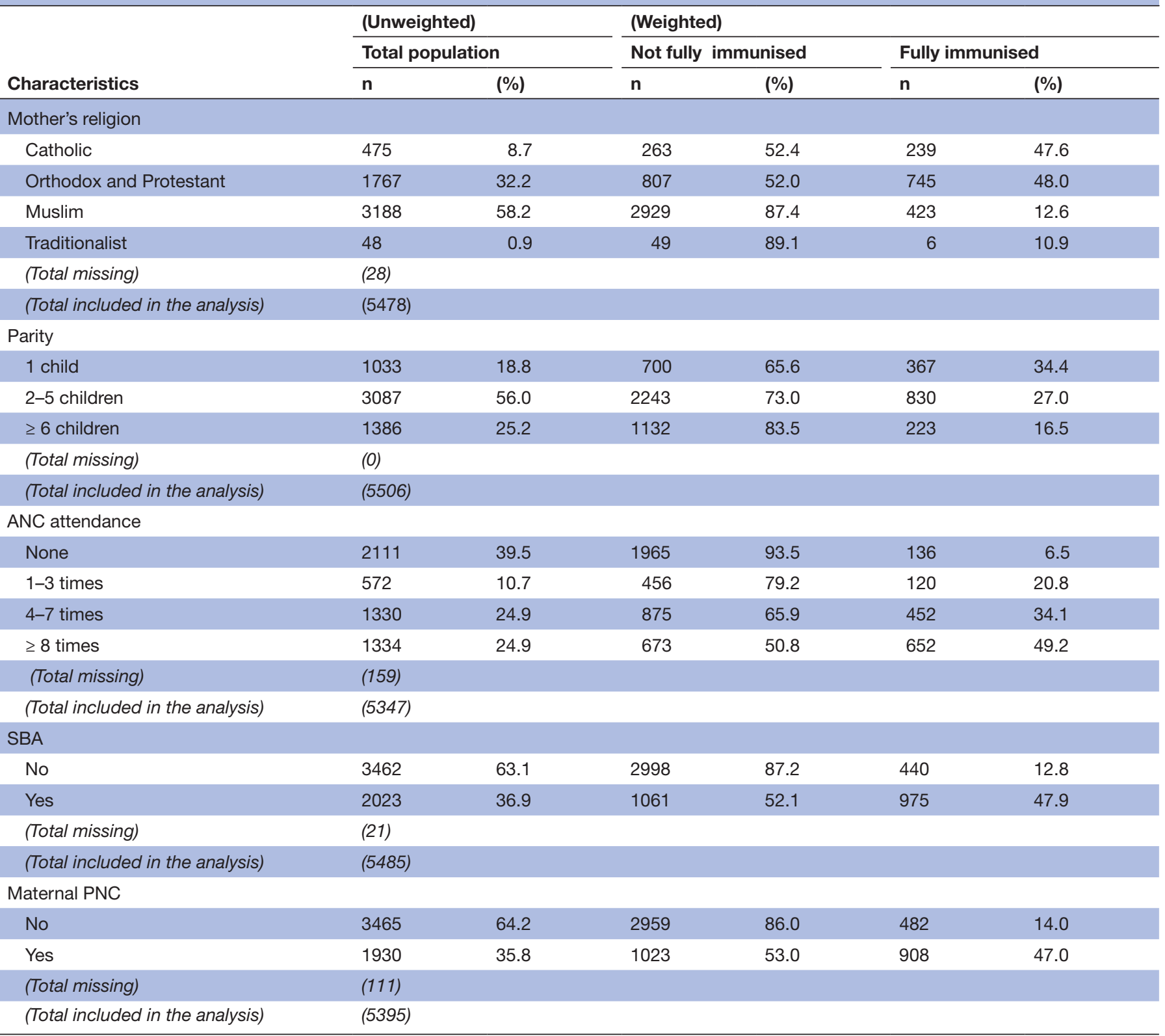

ANC, antenatal care; PNC, postnatal care; SBA, skilled birth attendance.

mothers who had four to seven ANC visits (COR 7.5, 95\% CI 6.06 to 9.18 ) and mothers who had a minimum of eight ( $\geq 8)$ ANC visits (COR 13.9, 95\% CI 11.39 to 17.14 ) were more likely to have their children fully immunised than mothers who had no ANC. Mothers who used SBA were 6.3 times (COR 6.3, 95\% CI 5.49 to 7.15 ) more likely to have their children fully immunised than mothers who used no SBA. Mothers who received PNC were 5.5 times (COR 5.5, $95 \%$ CI 4.78 to 6.22 ) more likely to have their children fully immunised than mothers who received no PNC.

Multivariable logistic regression results

Multivariable logistic regression analyses for each predictor variable individually

The AOR with 95\% CI from the multivariable logistic regression analysis for each of the predictor variables individually are shown in table 3 , model 1 . For ANC attendance, mothers who had one to three ANC visits (AOR 2.4, $95 \%$ CI 1.79 to 3.27 ), mothers who had four to seven ANC visits (AOR 3.2, 95\% CI 2.52 to 4.13 ) and mothers who had zeight ANC visits (AOR 3.5, 95\% CI 2.64 to 4.50 ) were more likely to have their children fully immunised than mothers who had no ANC after adjusting for highest educational level, wealth index, geopolitical zone, place of residence, person who decides on mother's healthcare, parity, mother's occupation and mother's age. Regarding skilled birth attendance, mothers who used SBA were 1.9 times (AOR 1.9, 95\% CI 1.65 to 2.35) more likely to have their children fully immunised than mothers who used no SBA after adjusting for the same covariates as in model 1 above (table 3, model 1). Mothers who received PNC were 
Table 2 COR with $95 \% \mathrm{Cl}^{\star}$ for the association between maternal healthcare utilisation and routine immunisation coverage of children in Nigeria. Total $(n)=5506$. (Nigeria Demographic and Health Survey 2013)

\begin{tabular}{|c|c|c|c|c|c|}
\hline & Frequency & Cases n (\%) & & Significant & $95 \% \mathrm{Cl}^{*}$ \\
\hline Variables & $\mathbf{n}$ & Valid (\%) & Missing (\%) & $p$ value & COR (lower, upper) \\
\hline ANC attendance & & $5258(95.5)$ & $248(4.5)$ & & \\
\hline $1-3$ times & 561 & & & $<0.001$ & 3.8 (2.92 to 4.97$)$ \\
\hline 4-7 times & 1307 & & & $<0.001$ & 7.5 (6.06 to 9.18$)$ \\
\hline No & 3384 & & & 1 & (Reference) \\
\hline Yes & 2011 & & & $<0.001$ & 6.3 (5.49 to 7.15$)$ \\
\hline Maternal PNC & & $5308(96.4)$ & $198(3.6)$ & & \\
\hline No & 3395 & & & 1 & (Reference) \\
\hline
\end{tabular}

${ }^{*}$ All analyses are weighted.

ANC, antenatal care; Cl, confidence interval ; COR, crude OR; PNC, postnatal care; SBA, skilled birth attendance.

Table 3 Stepwise multivariable logistic regression analysis (AOR with $95 \% \mathrm{Cl}$ ) for the association between $\mathrm{MHC}$ utilisation and routine immunisation coverage of children in Nigeria. Total $(n)=5506$. (Nigeria Demographic and Health Survey 2013)

\begin{tabular}{|c|c|c|c|}
\hline & Model 1 & Model 2 & Model 3 \\
\hline Variables & AOR (lower, upper) & AOR (lower, upper) & AOR (lower, upper) \\
\hline \multicolumn{4}{|c|}{ ANC attendance } \\
\hline $1-3$ times & $2.4(1.79 \text { to } 3.27)^{\star}$ & $2.0(1.51 \text { to } 2.74)^{*}$ & $2.3(1.69 \text { to } 3.15)^{\star}$ \\
\hline 4-7 times & $3.2(2.52 \text { to } 4.13)^{*}$ & $2.6(2.07 \text { to } 3.37)^{\star}$ & $2.9(2.22 \text { to } 3.76)^{\star}$ \\
\hline No & (Reference) & (Reference) & (Reference) \\
\hline Yes & $1.9(1.65 \text { to } 2.35)^{\star}$ & $1.5(1.27 \text { to } 1.83)^{\star}$ & $1.4(1.06 \text { to } 1.73)^{\star \star}$ \\
\hline \multicolumn{4}{|c|}{ Maternal PNC } \\
\hline No & (Reference) & & (Reference) \\
\hline
\end{tabular}

Model 1: Adjusted for highest educational level, wealth index, geopolitical zone, place of residence, person who decides on mother's healthcare, parity, mother's occupation and mother's age (in years).

Model 2:

ANC: Adjusted for variables in model 1 and SBA.

SBA: Adjusted for variables in model 1 and ANC attendance.

Model 3:

ANC: Adjusted for variables in model 2 and maternal PNC.

SBA: Adjusted for variables in model 2 and maternal PNC.

PNC: Adjusted for variables in model 1, SBA and ANC attendance.

${ }^{*} p<0.001$.

${ }^{* *} \mathrm{p}<0.05$.

ANC, antenatal care; AOR, adjusted OR; MHC, maternal healthcare; PNC, postnatal care; SBA, skilled birth attendance.

1.7 times (AOR 1.7, 95\% CI 1.46 to 2.06) more likely to have their children fully immunised than mothers who received no PNC after adjusting for the same covariates as in model 1 (table 3 , model 1 ).

Stepwise multivariable logistic regression analyses

The adjusted ORs with 95\% CI for the stepwise multivariable logistic regression analysis are shown in table 3; models 2 and 3. In model 2, mothers who had one to three ANC visits (AOR 2.0, 95\% CI 1.51 to 2.74), mothers who had four to seven ANC visits (AOR 2.6, 95\% CI 2.07 to 3.37) and mothers who had zeight ANC visits (AOR 2.7, 95\% CI 2.05 to 3.53 ) were more likely to have their children fully immunised than mothers who had no ANC after adjusting for SBA, highest educational level, wealth 
index, geopolitical zone and mother's age. Also, mothers who used SBA were 1.5 times (AOR 1.5, 95\% CI 1.27 to 1.83) more likely to have their children fully immunised than mothers who used no SBA after adjusting for ANC attendance, highest educational level, wealth index, geopolitical zone, place of residence, person who decides on mother's healthcare, parity, mother's occupation and mother's age (table 3 , model 2 ).

In model 3, mothers who had one to three ANC visits (AOR 2.3, 95\% CI 1.69 to 3.15), mothers who had four to seven ANC visits (AOR 2.9, 95\% CI 2.22 to 3.76) and mothers who had zeight ANC visits (AOR 2.9, 95\% CI 2.18 to 3.90 ) were more likely to have their children fully immunised than mothers who had no ANC after adjusting for SBA, maternal PNC, highest educational level, wealth index, geopolitical zone, place of residence, person who decides on mother's healthcare and mother's age. Also, mothers who used SBA were 1.4 times (AOR 1.4, 95\% CI 1.06 to 1.73 ) more likely to have their children fully immunised than mothers who used no SBA after adjusting for ANC attendance, maternal PNC, highest educational level, wealth index, geopolitical zone, place of residence, person who decides on mother's healthcare, parity, mother's occupation and mother's age. There was no significant association with maternal PNC (AOR 1.2, 95\% CI 0.92 to 1.47 ) after adjusting for ANC attendance, SBA, highest educational level, wealth index, geopolitical zone, place of residence, person who decides on mother's healthcare, parity, mother's occupation and mother's age (table 3, model 3).

\section{DISCUSSION}

This study examined the impact of MHC utilisation on routine immunisation coverage of children in Nigeria. The percentage of fully immunised children aged 12-23 months was $25.8 \%$, indicating a very low percentage of fully immunised children in Nigeria. However, this study showed that MHC utilisation seemed to be yielding positive results with respect to routine immunisation coverage of children in Nigeria. ANC attendance, SBA and maternal PNC showed significant effect on the child being fully immunised in Nigeria irrespective of socioeconomic status, geopolitical zone, place of residence, parity, person who decides on mother's healthcare and mother's age. There was a mediation effect on the association between maternal PNC and the child being fully immunised that led to the disappearance of the significant effect of PNC after adjusting for ANC attendance and SBA.

This study showed that, irrespective of the number of ANC visits by the mother, those who had ANC attendance had higher likelihood of having their children fully immunised than mothers who had no ANC attendance. This is consistent with studies in Senegal, ${ }^{35}$ Bangladesh, ${ }^{36}$ Indonesia, ${ }^{37}$ India, ${ }^{38}$ and Zimbabwe,${ }^{39}$ which showed that ANC attendance of the mother was significantly associated with increased likelihood of a child to be fully immunised.
In contrast, Lakew et $a l^{40}$ showed that ANC attendance was not associated with fully immunised children in Ethiopia. ${ }^{40}$ Although the finding by Lakew et $a t^{40}$ stands out among other findings, it calls for caution while making conclusions regarding the impact of ANC attendance on routine immunisation coverage of children. For instance, in that same study, the disappearance of the association of ANC attendance could be due to over adjustment of covariates. However, there could be differentials between countries regarding the impact of ANC attendance on routine immunisation coverage of children due to many factors such as socio-demographic factors and the quality of MHC services. ${ }^{41}{ }^{41}$ Despite the differences in documentations of the impact of ANC attendance on routine immunisation coverage of children, the chance of a child to be fully immunised would increase with ANC attendance of the mother.

Regarding the number of ANC visits by the mother, the likelihood of the child to be fully immunised increased with increasing number of ANC visits. This finding is consistent with studies that showed that the likelihood of fully immunised children increased with increasing number of ANC visits in low-income and lower-middle-income countries. ${ }^{42}{ }^{43}$ It is important to reiterate that the WHO has increased the recommended number of ANC visits from a minimum of four visits to at least eight visits (ie, the eight-visit model). ${ }^{29} 3044$ The minimum of eight ANC visits is to increase the opportunity of early detection and prevention of potential pregnancy complications and other maternal and child health problems. ${ }^{29}{ }^{3044}$ Interestingly, this study has shown that the new eight-visit model of ANC attendance has much higher positive effect on routine immunisation coverage of children than the previous four-visit model; and this can be explained by several factors.

The higher positive effect of the eight-visit model of ANC attendance on the child being fully immunised could be due to greater amount of information about immunisation services, education on the benefits of routine immunisation and better quality of immunisation services which are associated with increasing number of ANC visits. ${ }^{30} 4546$ The WHO's new ANC model stresses clearly the need for mothers to receive relevant, adequate and quality information and care during ANC attendance. ${ }^{30}$ Studies have shown that a lot of maternal and child health information/education is provided to mothers during ANC attendance. ${ }^{30}{ }^{46}$ Hence, with increasing number of ANC visits mothers become increasingly aware of immunisation services and the benefits of immunising their children after delivery. For instance, a study that examined the determinants of immunisation coverage in a district of Nigeria showed that good knowledge of mothers about immunisation and being aware of the benefits of immunisation services were positively associated with fully immunised children. ${ }^{47}$ Despite the positive effect of the eight-visit model of ANC attendance on the child being fully immunised, close to half of the mothers in this study received no ANC. Therefore, there is a need 
for appropriate public health interventions such as the establishment of rural health facilities and conditional cash transfer programmes targeted at under-served areas in order to increase ANC attendance among mothers.

This study showed that mothers who used SBA had a higher likelihood of having their children fully immunised than mothers who used no SBA. This finding is consistent with studies that were conducted in low-income and lower-middle-income countries which showed that health facility delivery was positively associated with children being fully immunised. ${ }^{3537394248}$ In contrast, Lakew et at $t^{40}$ and Herliana and Douiri ${ }^{37}$ showed that mothers whose babies were delivered in health institutions were less likely to be fully immunised compared with mothers who deliver at home in Ethiopia and Indonesia. ${ }^{37} 40$ The contrasting findings regarding the effect of mothers' use of SBA on the child being fully immunised show that health facility delivery without proper implementation of routine immunisation services would not contribute much in increasing routine immunisation coverage of children. Also, the importance of educating mothers on the benefits of routine immunisation for children even in the second phase on the MHC continuum (ie, when using SBA) cannot be overemphasised. ${ }^{30} 45$

The assessment of the individual effect of SBA indicated that SBA had a lower effect on the child being fully immunised compared with ANC attendance. Many factors could explain this finding. For instance, Chukwuma et $a l^{46}$ showed that the likelihood of retention in SBA was higher among mothers who received high quality services during ANC attendance compared with mothers who received low quality services during ANC attendance. ${ }^{46}$ Chukwuma $e t a t^{46}$ showed that only $66 \%$ of mothers who received ANC continued to use SBA in 28 African countries, inclusive of Nigeria. ${ }^{46}$ The lower effect of SBA on the child being fully immunised could also be due to insufficient MHC/immunisation communication interventions and socio-demographic factors such as the location of health facility, high cost of health services and cultural practices which could be barriers to mother's use of SBA which may subsequently lead to a child not being fully immunised. 3640414549

This study showed that mothers who received PNC had higher likelihood of having their children fully immunised than mothers who received no PNC. This finding is consistent with studies in Ethiopia, Indonesia and in other low-income and lower-middle-income countries which showed that the likelihood of a child to be fully immunised was higher among mothers who received PNC compared with mothers who received no PNC. ${ }^{37} 4042$ The disappearance of the significant effect of maternal PNC after adjusting for ANC attendance and SBA could be explained by mediation rather than confounding considering the sequence of MHC, that is, ANC-SBA-PNC; hence, this finding does not suggest that PNC has no effect on the child being fully immunised.

With respect to the impact of MHC utilisation holistically on routine immunisation coverage of children in
Nigeria, this study provides a strong evidence of the positive impact of MHC utilisation on routine immunisation coverage of children. This is consistent with Meleko et $a t^{43}$ which stressed that MHC utilisation was associated with increased likelihood of the child to be fully immunised in Southwest Ethiopia. ${ }^{43}$

\section{Strengths and limitations}

The reliability of this study is increased by the quality of the NDHS woman's questionnaire which is a carefully developed standard model questionnaire. ${ }^{21}$ The NDHS which is a nationally representative survey provided a large sample size and high-quality data which reduced the risk of sampling bias and measurement bias in this study. Another strength of this study is in its design; confounding was controlled for through the proper formation of subcategories of the predictor variables and covariates. The consideration of a wide range of covariates in the multivariable logistic regression analysis which reduced the risk of confounding increased the internal validity of this study. ${ }^{50}$

However, there are a number of limitations in this study. First, the NDHS questionnaires are administered by the interviewers during the survey data collection; hence, the data is prone to interviewer bias which could reduce the internal validity of this study. However, the NDHS questions are standardised and very detailed and therefore reduces the chances of an interviewer bias. Second, the inclusion of immunisation status of the children from verbal reports of the mother might have introduced recall bias into this study because mothers who used MHC may have a better recall than mothers who used no MHC. ${ }^{350}$ Also, recall bias might have been introduced into this study because of the selection of last birth experience of mothers in the 5 years preceding the survey in 2013. Mothers who had more than one child in that period might have difficulty recalling their last birth experience. Furthermore, the inclusion of immunisation status of the children from verbal reports of the mothers might have introduced differential misclassification into this study due to potential under-reporting of children who were not fully immunised. This is because mothers can provide false reports about the immunisation status of their children in the absence of health cards of their children in order to appear socially acceptable. ${ }^{51}$ Third, there is still a risk of residual confounding even after controlling for confounding in this study. Fourth, the non-exploration of partially immunised children might have led to loss of information regarding routine immunisation coverage in Nigeria. Finally, vaccine stockouts, poor cold chain systems and non-readiness of healthcare providers to administer the vaccines during mothers' use of maternal health services in Nigeria are provider side barriers to the child being fully immunised, which could have led to an underestimation of the impact of MHC utilisation on routine immunisation coverage found in this study. 


\section{CONCLUSIONS}

This study examined the impact of MHC utilisation on routine immunisation coverage of children in Nigeria. This study has achieved its aim to examine the impact of MHC utilisation on routine immunisation coverage of children in Nigeria. Therefore, reliable conclusions can be drawn from this study. Routine immunisation coverage of children in Nigeria was well below the national immunisation target rate of $80 \%$. ANC attendance of the mother, mother's use of SBA at delivery and PNC attendance of the mother had positive impact on the child being fully immunised. The findings suggest that strategies aimed at maximising MHC utilisation in Nigeria could be effective in achieving the national coverage target of at least $80 \%$ for routine immunisation of children.

Strategies that can maximise MHC utilisation in Nigeria need to focus on promoting access to MHC especially in under-served rural communities. To achieve this, it is important that health facilities are located in close proximity to rural areas in order to reduce the travel time to health facilities. Also, provision of free transportation to health facilities that are located in far distance from rural communities can reduce barriers arising from distance and cost of transportation. Most importantly, provider side barriers can be minimised by ensuring that health professionals who are trained in MHC are available and willing to provide quality care to mothers. Furthermore, other public health interventions such as free maternal health services at the point of care, conditional cash transfer and awareness campaign on the benefits of MHC are needed.

Contributors OIA: conceptualised the research study, developed the study design, acquired data, analyzed and drafted the manuscript. BOA: involved in developing the study design, interpretation and contributed to the writing of the manuscript. All authors read and approved the final draft of the manuscript.

Funding The authors have not declared a specific grant for this research from any funding agency in the public, commercial or not-for-profit sectors.

Competing interests None declared.

Patient consent for publication Not required.

Ethics approval A request to download and use the NDHS 2013 dataset for this study was submitted to the DHS Program in charge of the dataset. The DHS Program is a United States Agency for International Development (USAID) funded project. The permission to download and use the NDHS 2013 dataset for this study was given. The NDHS 2013 dataset contained no personal information of the respondents. The questionnaires and procedures used in the NDHS 2013 were reviewed and approved by the International Classification of Functioning, Disability and Health (ICF) Institutional Review Board in Nigeria. The procedure for informed consent in the NDHS 2013 was that the respondents gave verbal informed consent which was then signed by the interviewer prior to the interview.

Provenance and peer review Not commissioned; externally peer reviewed.

Data sharing statement The datasets used for this study are available on request from the DHS Program [at http://dhsprogram.com/data/available-datasets.cfm].

Open access This is an open access article distributed in accordance with the Creative Commons Attribution Non Commercial (CC BY-NC 4.0) license, which permits others to distribute, remix, adapt, build upon this work non-commercially, and license their derivative works on different terms, provided the original work is properly cited, appropriate credit is given, any changes made indicated, and the use is non-commercial. See: http:// creativecommons.org/licenses/by-nc/4.0/.
REFERENCES

1. de Castro F, Hubert C, Strand E, et al. Severe functional difficulties and disabilities in children and adolescents and the Sustainable Development Goals. Salud Publica Mex 2017;59:354-60.

2. Guerrera G. Neonatal and pediatric healthcare worldwide: a report from UNICEF. Clin Chim Acta 2015;451:4-8.

3. United Nations Inter-agency Group for Child Mortality Estimation. Levels \& trends in child mortality: report 2017. New York: United Nations Children's Fund, 2017.

4. Machingaidze S, Wiysonge CS, Hussey GD. Strengthening the expanded programme on immunization in Africa: looking beyond 2015. PLoS Med 2013;10:e1001405-5.

5. Kc A, Nelin V, Raaijmakers $\mathrm{H}$, et al. Increased immunization coverage addresses the equity gap in Nepal. Bull World Health Organ 2017;95:261-9.

6. Jit M, Dang TT, Friberg I, et al. Thirty years of vaccination in Vietnam: Impact and cost-effectiveness of the national Expanded Programme on Immunization. Vaccine 2015;33:A233-A239.

7. Oyo-Ita A, Wiysonge CS, Oringanje C, et al. Interventions for improving coverage of childhood immunisation in low- and middleincome countries. Cochrane Database Syst Rev 2016;7:1-93.

8. Henderson RH. The expanded programme on immunization of the world health organization. Rev Infect Dis 1984;6:S475-S479.

9. Wiysonge CS, Uthman OA, Ndumbe PM, et al. A bibliometric analysis of childhood immunization research productivity in Africa since the onset of the Expanded Program on Immunization in 1974. BMC Med 2013;11:1-10.

10. Babaniyi OA. A 10-year review of morbidity from childhood preventable diseases in Nigeria: how successful is the expanded programme on immunization (EPI)? An update. J Trop Pediatr 1990;36:306-13.

11. Duclos P, Okwo-Bele JM, Gacic-Dobo M, et al. Global immunization: status, progress, challenges and future. BMC Int Health Hum Rights 2009;9:S2.

12. Sorungbe AO. Expanded Programme on Immunization in Nigeria Rev Infect Dis 1989;11:S509-S511.

13. Gunnala R, Ogbuanu IU, Adegoke OJ, et al. Routine vaccination coverage in northern nigeria: results from 40 district-level cluster surveys, 2014-2015. PLoS One 2016;11:e0167835-14.

14. Morakinyo OM, Fagbamigbe AF. Neonatal, infant and under-five mortalities in nigeria: an examination of trends and drivers (20032013). PLoS One 2017;12:e0182990-21.

15. Akinyemi JO, Bamgboye EA, Ayeni O. Trends in neonatal mortality in Nigeria and effects of bio-demographic and maternal characteristics. BMC Pediatr 2015;15:1-12.

16. Oluoha $\mathrm{C}$, Umeh $\mathrm{C}$, Ahaneku $\mathrm{H}$. Assessing the contributions of private health facilities in a pioneer private-public partnership in childhood immunization in Nigeria. J Public Health Africa 2014;5:40-2.

17. Obasola OI, Mabawonku IM. Women's use of information and communication technology in accessing maternal and child health information in Nigeria. Afr J Libr Arch Inform Sci 2017;27:1-15.

18. Akinyemi JO, Afolabi RF, Awolude OA. Patterns and determinants of dropout from maternity care continuum in Nigeria. BMC Pregnancy Childbirth 2016;16:1-11.

19. Ushie BA, Fayehun OA, Ugal DB. Trends and patterns of under-5 vaccination in Nigeria, 1990-2008: what manner of progress? Child Care Health Dev 2014;40:267-74.

20. Erchick DJ, George AS, Umeh C, et al. Understanding internal accountability in nigeria's routine immunization system: perspectives from government officials at the national, state, and local levels. Int $J$ Health Policy Manag 2017;6:403-12.

21. National Population Commission Nigeria. Nigeria demographic and health survey 2013. 2014 https://dhsprogram.com/pubs/pdf/fr293/ fr293.pdf

22. Mallick L, Tukur D, Kerry LDM. Trends in maternal health care in Nigeria, 2003 - 2013. 2016 https://dhsprogram.com/pubs/pdf/FA102/ FA102.pdf

23. United Nations. Sustainable development goals. 2017 http://www.un org/sustainabledevelopment/sustainable-development-goals/

24. Antai D. Rural-urban inequities in childhood immunisation in Nigeria: The role of community contexts. Afr J Prim Health Care Fam Med 2011;3:82-9.

25. Kazungu JS, Adetifa IMO. Crude childhood vaccination coverage in West Africa: Trends and predictors of completeness. Wellcome Open Res 2017;2:12-23.

26. Moyer CA, Benyas D, Rominski S. The relationship between facilitybased delivery and infant immunization in sub-Saharan Africa. Afr J Reprod Health 2016;20:27-33. 
27. Ataguba JE, Ojo KO, Ichoku HE. Explaining socio-economic inequalities in immunization coverage in Nigeria. Health Policy Plan 2016;31:1212-24.

28. Eboreime E, Abimbola S, Bozzani F. Access to routine immunization: a comparative analysis of supply-side disparities between Northern and Southern Nigeria. PLoS One 2015;10:e0144876-10.

29. World Health Organization. WHO recommendations on antenatal care for a positive pregnancy experience. Geneva: World Health Organization, 2016a.

30. Tunçalp Ö, Pena-Rosas JP, Lawrie T, et al. WHO recommendations on antenatal care for a positive pregnancy experience-going beyond survival. BJOG 2017;124:860-2.

31. World Health Organization. WHO Recommendations on Postnatal Care of the Mother and Newborn. Geneva: World Health Organization, 2013.

32. Bowers D. Medical Statistics from Scratch: An Introduction for Health Professionals. 3rd ed. Chichester: John Wiley, 2014.

33. Pallant J. SPSS survival manual: a step by step guide to data analysis using IBM SPSS. 5th ed. Maidenhead: McGraw-Hill, 2013.

34. USAID. Standard Recode Manual for DHS 6. 2013 https://www. dhsprogram.com/pubs/pdf/DHSG4/Recode6_DHS_22March2013_ DHSG4.pdf

35. Mbengue MAS, Sarr M, Faye A, et al. Determinants of complete immunization among senegalese children aged 12-23 months: evidence from the demographic and health survey. BMC Public Health 2017;17:630-8.

36. Boulton ML, Carlson BF, Power LE, et al. Socioeconomic factors associated with full childhood vaccination in Bangladesh, 2014. Int J Infect Dis 2018;69:35-40.

37. Herliana P, Douiri A. Determinants of immunisation coverage of children aged 12-59 months in Indonesia: a cross-sectional study. BMJ Open 2017;7:e015790-14.

38. Sahu D, Pradhan J, Jayachandran V, et al. Why immunization coverage fails to catch up in India? A community-based analysis. Child Care Health Dev 2010;36:332-9.

39. Mukungwa T. Factors associated with full immunization coverage amongst children aged $12-23$ months in Zimbabwe. African Population Studies 2015;29:1761-74.
40. Lakew Y, Bekele A, Biadgilign S. Factors influencing full immunization coverage among 12-23 months of age children in Ethiopia: evidence from the national demographic and health survey in 2011. BMC Public Health 2015:15:1-8.

41. Oleribe O, Kumar V, Awosika-Olumo A, et al. Individual and socioeconomic factors associated with childhood immunization coverage in Nigeria. Pan Afr Med J 2017;26:1-14.

42. Restrepo-Méndez MC, Barros AJ, Wong KL, et al. Missed opportunities in full immunization coverage: findings from low- and lower-middle-income countries. Glob Health Action 2016;9:30963-6.

43. Meleko A, Geremew M, Birhanu F. Assessment of child immunization coverage and associated factors with full vaccination among children aged 12-23 months at Mizan Aman Town, Bench Maji Zone, Southwest Ethiopia. Int J Pediatr 2017;2017:1-11.

44. World Health Organization. Opportunities for Africa's Newborns. Cape Town: Mills Litho, 2016b.

45. Oku A, Oyo-Ita A, Glenton C, et al. Factors affecting the implementation of childhood vaccination communication strategies in Nigeria: a qualitative study. BMC Public Health 2017;17:200-11.

46. Chukwuma A, Wosu AC, Mbachu C, et al. Quality of antenatal care predicts retention in skilled birth attendance: a multilevel analysis of 28 African countries. BMC Pregnancy Childbirth 2017;17:152-62.

47. Adedire EB, Ajayi I, Fawole OI, et al. Immunisation coverage and its determinants among children aged 12-23 months in Atakumosa-west district, Osun State Nigeria: a cross-sectional study. BMC Public Health 2016;16:1-8.

48. Moyer CA, Tadesse L, Fisseha S. The relationship between facility delivery and infant immunization in Ethiopia. Int J Gynaecol Obstet 2013;123:217-20.

49. Narváez J, Osorio MB, Castañeda-Orjuela C, et al. Is Colombia reaching the goals on infant immunization coverage? A quantitative survey from 80 municipalities. Vaccine 2017;35:1501-8.

50. Aschengrau A, Seage GR. Essentials of epidemiology in public health. 3rd ed. Burlington: Jones, 2014.

51. Leggett CG, Kleckner NS, Boyle KJ, et al. Social desirability bias in contingent valuation surveys administered through in-person interviews. Land Econ 2003;79:561-75. 